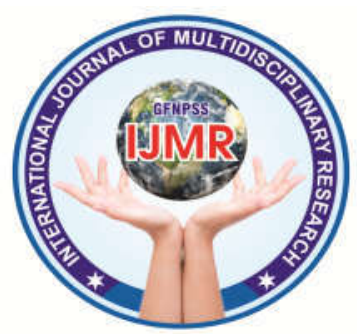

\title{
A STUDY TO ASSESS THE EFFECTIVENESS OF SELF-INSTRUCTIONAL MODULE ON KNOWLEDGE REGARDING NON-PHARMACOLOGICAL MANAGEMENT OF DYSMENORRHEA AMONG ADOLESCENT GIRLS IN DESH BHAGAT UNIVERSITY SCHOOL COLLEGE OF NURSING MANDI GOBINDGARH, PUNJAB
}

\author{
Shivani Sharma ${ }^{1}$ Professor Deepak K Shandilya ${ }^{2}$ \\ ${ }^{1}$ DeshBhagat University School of Nursing, MandiGobindgarh, Punjab, 147301, India \\ ${ }^{2}$ Vice Principal, Department of MentalHealth Nursing, DeshBhagat University School of \\ Nursing, Mandi Gobindgarh, Punjab, 147301, India
}

Corresponding Email: shivanisharmap301@gmail.com

\section{ABSTRACT}

Introduction: Adolescence is a transition period from childhood to adulthood and is characterized by a spurt in physical, endocrinal, emotional, and mental growth, with a change from complete dependence to relative independence. The period of adolescence for a girl is a period of physical and psychological preparation for safe motherhood.

Material \& Methods - It The sample size was 60 adolescent girls between the age group of 1821years. In this study setting is adolescent girls in Desh Bhagat University School of Nursing, Punjab. In this study samples were drawn by using simple random sampling method.

Results- The collected data was analyzed by using descriptive and inferential statistics ( $t$ test). Results revealed that post-test knowledge score $(\mathrm{x} 2=18.33)$ was higher than the mean pretest knowledge score $(\mathrm{x} 1=13.37)$. The results showed that the mean post-test knowledge score (23.5) was significantly higher than of the mean pre-test knowledge score (18.3) as evidenced by $\mathrm{t}=30.3(\mathrm{p}<0.05)$, and found to be significant at 0.05 level of significance, which indicated that self-instructional module was effective.'

Conclusion: This study has shown that Most of the adolescent girls in DeshBhagat University School College of Nursing MandiGobindgarh, Punjab had less knowledge regarding nonpharmacological management of dysmenorrhea.

Keywords Assess, Effectiveness, Information Booklet, Sample size, questionnaire 


\section{INTRODUCTION}

"We must turn to nature itself, to the observations of the body in health and in disease to learn the truth"

Adolescence is a transition period from childhood to adulthood and is characterized by a spurt in physical, endocrinal, emotional, and mental growth, with a change from complete dependence to relative independence. The period of adolescence for a girl is a period of physical and psychological preparation for safe motherhood. One of the major physiological changes that take place in adolescent girls is the onset of menarche which is often associated with problems of irregular menstruation, excessive bleeding and dysmenorrhea. Of these, dysmenorrhea is one of the common problems experienced by many adolescentgirls.

Adolescence is a time of moving from the immaturity of childhood into the maturity of adulthood. Period of life from puberty to adulthood characterized by marked physiological changes, development of sexual feelings, efforts towards the construction of identity and a progression from concrete to abstract thought. Puberty as well-known as is the period of life in all women generally between the ages of 10 to 15 years. Here it is important to remember that the puberty represents the earliest time of reproduction.

Menstruation on monthly periods is a part of every woman's life. It starts at puberty, at the age of 13-14 in females and continues till menopause that occurs at the age of 4550 year. The pain is much during adolescence, but disappears or lessens after childbirth. The Medical term for menstrual pain is 'Dysmenorrhea'. Pain usually occurs in the lower abdomen and pelvic regions. ${ }^{4}$

Dysmenorrhea is one of the most frequent gynecological disorders, affecting more than half of the menstruating adolescent girls. The incident and prevalence of dysmenorrhea are not clearly established. It concluded that dysmenorrhea (87.87\%) is a common problem in India and is one of the common problem experienced by many adolescent girls.

Dysmenorrhea also known as painful periods, or menstrual cramps pain during menstruation. Its usual onset occurs around the time that menstruation begins. . Estimates of the percentage of women of 


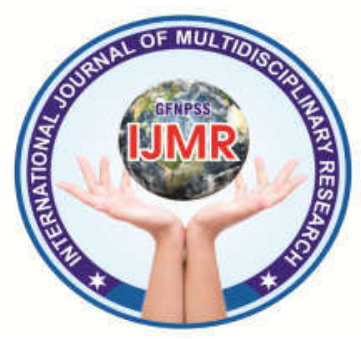

reproductive age affected varying from 20 to $90 \%$. Symptoms typically last less than three days .The main symptom of dysmenorrhea is pain concentrated in the lower abdomen or pelvis. It is also commonly felt in the right or left side of the abdomen. It may radiate to the thighs and lowerback.

Symptoms often co-occurring with menstrual pain including nausea and vomiting, diarrhea or constipation, headache, dizziness, disorientation, hypersensitivity to sound, light, smell and touch, fainting, and fatigue. Symptoms of dysmenorrhea often begin immediately after ovulation and can last until the end of menstruation. This is because dysmenorrhea is often associated with changes in hormonal levels in the body that occur with ovulation. Dysmenorrhea can be classified as either primary or secondary based on the absence or presence of an underlying cause. Primary dysmenorrhea occurs without an associated underlying condition, while secondary dysmenorrhea has a specific underlying cause, typically a condition that affects the uterus or other reproductiveorgans.

Dysmenorrhea complications are pain consists of suprapubic cramping and aching radiating down the anterior thighs and to the lumbosacral region, often accompanied by vomiting, fatigue, back pain, headaches, dizziness and diarrhea. The main complication of dysmenorrhea is pain. It occurs in your lower abdomen during menstruation and may also be felt in your hips, lower back, or thighs. Other symptoms may include nausea, vomiting, diarrhea, light headedness, or general achiness.

Dysmenorrhea pain may be spasmodic (sharp pelvic cramps at the start of menstrual flow) or congestive (deep, dull ache). The symptoms of secondary dysmenorrhea often start sooner in the menstrual cycle than those of primary dysmenorrhea, and usually last longer. In $5 \%$ to $15 \%$ of women with primary dysmenorrhea, the pain is severe enough to disturb their daily activities and may result in missed work or school.

\section{MATERIALS \&METHODS}

Quantitative Approach was used to assess the effectiveness of Self instructional module on knowledge regarding nonpharmacological management of dysmenorrhea among adolescent girls. A pre-experimental one group pre test posttest 


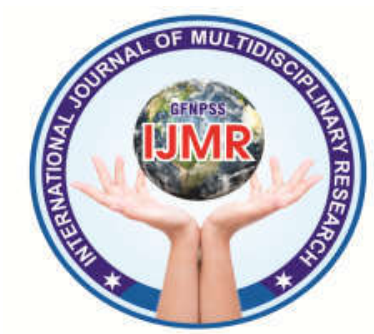

research design was used to assess the effectiveness of Self-instructional module on knowledge regarding non- pharmacological management of dysmenorrhea among adolescent girls in DeshBhagat University School of Nursing, MandiGobindgarh, Punjab.

\section{RESULTS}

To assess and compare the effectiveness of self-instructional module on knowledge regarding non-pharmacological management of dysmenorrhea among adolescent girls after administration of selfinstructional module. Sample Size -60

\begin{tabular}{|l|c|c|l|}
\hline \multicolumn{2}{|l|}{ CRITERIA MEASURE OF POSTTEST KNOWLEDGE SCORE } \\
\hline $\begin{array}{l}\text { Level of } \\
\text { knowledge }\end{array}$ & Grade & $\begin{array}{c}\text { Pos-test } \\
\text { score (f\%) }\end{array}$ & $\begin{array}{l}\text { Level of } \\
\text { knowledge }\end{array}$ \\
\hline $\begin{array}{l}\text { Inadequate } \\
\text { Knowledge }\end{array}$ & $0-10$ & $00(0.0 \%)$ & $\begin{array}{l}\text { Inadequate } \\
\text { Knowledge }\end{array}$ \\
\hline $\begin{array}{l}\text { Moderate } \\
\text { Knowledge }\end{array}$ & $11-20$ & $07(11.6 \%)$ & $\begin{array}{l}\text { Moderate } \\
\text { Knowledge }\end{array}$ \\
\hline $\begin{array}{l}\text { Adequate } \\
\text { Knowledge }\end{array}$ & $21-30$ & $53(88.4 \%)$ & $\begin{array}{l}\text { Adequate } \\
\text { Knowledge }\end{array}$ \\
\hline $\begin{array}{l}\text { Level of } \\
\text { knowledge }\end{array}$ & Grade & $\begin{array}{c}\text { Pos-test } \\
\text { score (f\%) }\end{array}$ & $\begin{array}{l}\text { Level of } \\
\text { knowledge }\end{array}$ \\
\hline
\end{tabular}

\section{Maximum score $=\mathbf{3 0} \quad$ Minimum score $=\mathbf{3 0}$}

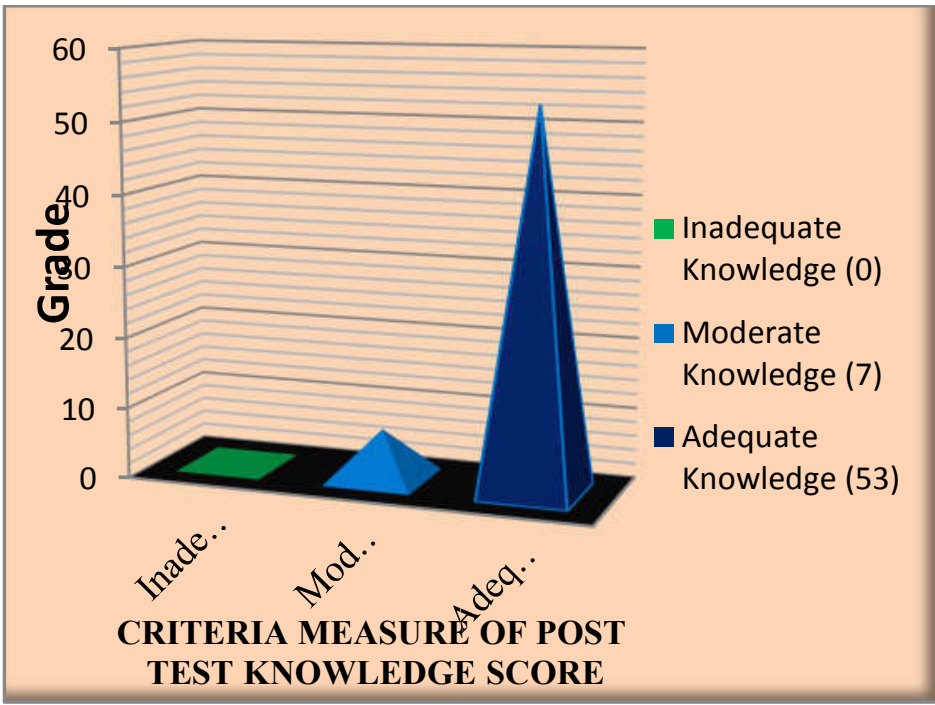

\section{CONCLUSION}

Out of 60 subjects less than half 28(46.8\%) had inadequate knowledge, more than half $32(53.2 \%)$ had moderate knowledge and none 00(0.0\%) were having adequate knowledge regarding nonpharmacological management of dysmenorrhea. In post- test none $00(0.0 \%)$ were having inadequate knowledge, less than $1 / 4^{\text {th }} 07(11.6 \%)$ were having moderate knowledge and majority of 53(88.4\%) have gained adequate knowledge regarding nonpharmacological management of dysmeno rrhea. 


\section{REFRENCES}

1. Anil K Agarwal\&AnjuAgarwal; Indian Journal of Community Medicine 2010 January (A study of dysmenorrhoea during menstruation in adolescent girls).

2. Adolescent:

URL:http//www.Answers.com/Topic

/Adolescents [2010 Dec2].

3. Nair Parvathy, Grover Vijay L, Kannan AT. Awareness and practices of menstruation and pubertal changes amongst unmarried female adolescents in a rural area of East Delhi. Indian Journal of Community Medicine, April2007; 32(2):2007-08.

4. Sharma P, Malhotra C, Taneja DK, Saha R. Problems releated to menstruation among adolescent girls. Indian J. pediatr 2009 Feb;75(2):125-9.

5. Uhr Women's Health about Cures.

The Difficulty with Dysmenorrhea (painful cramps) January 2008; 17:44.

6. Osayande AS; Mehulie S; March 2014; Diagonosis\& Initial management of dysmenorrhoea.

7. Period pain Medline plus; National library of Medicine; March 1,2018 retrieved November7,2018.

8. Gagua,T; Tkeshelashvii, B, Gagua, D; \& MC Hwdlishvili N. (2103). Assessment of sanxiety and depression in adolescent with primary dysmenorrhea: A case control study. J pediatradolesc Gynecol. 26(6):350-4.

9. Effect of Aromatherapy abdominal massage using peppermint versus ginger oils on primary dysmenorrhea among adolescent girls.Journal of American Science 2013;9(11); http://www.Jofaerican science.org. 